\begin{tabular}{|l|l|l||}
\hline \multicolumn{2}{|c|}{ PublisherInfo } \\
\hline \hline PublisherName & $:$ & BioMed Central \\
\hline \hline PublisherLocation & $:$ & London \\
\hline \hline PublisherImprintName & $:$ & BioMed Central \\
\hline \hline
\end{tabular}

\title{
Survival following AAA repair
}

\begin{tabular}{|l|l|l||}
\hline \multicolumn{2}{|c||}{ ArticleInfo } \\
\hline \hline ArticleID & $:$ & 4255 \\
\hline \hline ArticleDOI & $:$ & $10.1186 /$ ccf-2000-5178 \\
\hline \hline ArticleCitationID & $:$ & 5178 \\
\hline \hline ArticleSequenceNumber & $:$ & 43 \\
\hline \hline ArticleCategory & $:$ & Paper Report \\
\hline \hline ArticleFirstPage & $:$ & 1 \\
\hline \hline ArticleLastPage & $:$ & 3 \\
\hline \hline & & RegistrationDate : 2000-5-12 \\
\hline ArticleHistory & $:$ & OnlineDate \\
\hline \hline ArticleCopyright & $:$ & Current Science Ltd2000-5-12 \\
\hline \hline ArticleGrants & $:$ & \\
\hline \hline ArticleContext & $:$ & 1305433 \\
\hline \hline
\end{tabular}


Richard Venn, ${ }^{\text {Aff1 }}$

Aff1 St George's Hospital, London

\section{Keywords}

Abdominal aortic aneurysm, mortality, rupture, outcome

\section{Comments}

Despite the relatively small patient numbers in this study, the results are interesting and important conclusions can be drawn. Hospital mortality remains high (69\%) following emergency repair of ruptured emergency abdominal aortic aneurysm (AAA), results from this study parallel other study findings that survival rate is relatively static, remaining similar to survival rate for elective AAA repair if you are discharged from hospital. For this population, there was no difference in outcome between operations performed by vascular and nonvascular surgeons. This fits with other observations that a major determinant of survival is pre-operative hypotension, ie the shorter the time to cross-clamping, the better the survival. This conflicts with the 'hub and spoke' policy for vascular services, where ruptured AAAs are transferred from the district general hospital (DGH) to a vascular centre for surgery, which inevitably prolongs the time to cross-clamping. Definitive surgery should occur rapidly at the point of entry into the hospital system, and this may mean the vascular surgeon travelling to the patient if survival is to be improved. Finally, we need to address the problem of the appalling survival rate in those aged over 80 years, and decide on whether we should be offering a scarce resource (intensive therapy unit [ITU] bed) to patients with a hopeless outcome. It is to be hoped that the audit by the Vascular Anaesthetic Society will provide us with more extensive data with which to make these important decisions.

\section{Introduction}

Emergency AAA repair carries a mortality of greater than $50 \%$, in contrast to figures quoted for elective repair of $1.5-7 \%$. Patients with AAA greater than $5 \mathrm{~cm}$ in diameter have a 5 year survival of $25 \%$ without an operation. This study examines the 5 year mortality data for emergency AAA repair in a $\mathrm{DGH}$ in the UK.

\section{Methods}


.5 year retrospective observational study.

. Outcome: Survival following emergency surgery for AAA rupture.

\section{Results}

Ninety nine patients, with a mean age of 75.2 years, underwent emergency surgery for AAA rupture over the study period. Operating theatre survival was $75.8 \%$, postoperative ITU survival was $40.4 \%$, and overall hospital survival $31.3 \%$ (compared to $96 \%$ hospital survival for elective AAA repair). At the end of the follow-up period 22/99 (22.2\%) patients were still alive (median survival 4.4 years). Mean length of ITU stay was 6.8 days for survivors and 7.9 days for those who died in hospital. Eleven patients required haemofiltration, but no patients required long-term dialysis. Twenty-six percent of patients were aged over 80 years and the mortality of this group was $96 \%$.

\section{References}

1. Milner QJW, Burchett KR: Long-term survival following emergency abdominal aortic aneurysm repair. Anaesthesia. 2000, 55: 432-435. 